\title{
QUANDO O TEMPO NARRATIVO ULTRAPASSA O TEMPO DA CLÍNICA: UM MODO DE CUIDAR EM ENFERMAGEM NO PERÍODO PÓS-NATAL ${ }^{1}$ WHEN THE NARRATIVE PERIOD LASTS LONGER THAN CLINICAL PERIOD: A METHOD FOR POST-NATAL NURSING CARE \\ CUANDO EL TIEMPO NARRATIVO SOBREPASA EL TIEMPO DE LA CLÍNICA: UNA MANERA DE CUIDAR EN LA ENFERMERÍA DURANTE EL PERÍODO POST-NATAL
}

\author{
Marisa Monticelli2 Ingrid Elsen ${ }^{3}$
}

\begin{tabular}{l}
${ }^{1}$ Este trabalho faz parte de uma pesquisa maior que se constituiu na Tese de Doutorado da primeira autora, denominada: "Aproximações \\
culturais entre trabalhadoras de enfermagem e famílias no contexto do nascimento hospitalar: uma etnografia de alojamento conjunto", \\
defendida em 2003, na Universidade Federal de Santa Catarina/UFSC - Brasil. \\
${ }^{2}$ Enfermeira. Doutora em Enfermagem. Professora Adjunto IV dos Cursos de Graduação e Pós-Graduação do Departamento de \\
Enfermagem da UFSC. Membro do Núcleo de Extensão e Pesquisa em Educação Popular e Saúde (NEPEPS). \\
${ }^{3}$ Enfermeira. Doutora em Enfermagem. Professora do Programa de Mestrado Profissionalizante em Saúde da Universidade do Vale do \\
Itajaí/UNIVALI - Brasil. Professora Colaboradora do Programa de Pós-Graduação em Enfermagem da UFSC. Fundadora do Grupo \\
de Assistência, Pesquisa e Educação na Área da Saúde da Família (GAPEFAM). Orientadora da Tese. \\
\hline
\end{tabular}

PALAVRAS-CHAVE: Alojamento conjunto. Cultura. Cuidados de enfermagem.

KEYWORDS: Rooming in care. Culture. Nursing care.

PALABRAS CLAVE:

Alojamiento conjunto. Cultura. Atención de Enfermería.
RESUMO: Investigação de natureza qualitativa, com o objetivo de compreender a rede de símbolos e significados expressa na vivência do tempo narrativo entre trabalhadoras de enfermagem e famílias em uma unidade de Alojamento Conjunto de uma Maternidade pública. O suporte teórico esteve fundamentado em estudos antropológicos que utilizam narrativas terapêuticas para coleta e interpretação dos dados de pesquisa. Para a coleta de dados foram utilizadas as técnicas de observação participante e entrevista etnográfica. O processo de categorização e análise dos dados foi construído com base na Etnoenfermagem. Os resultados principais assinalam que, no contexto investigado, as trabalhadoras atuam buscando a transformação do tempo clínico em tempo narrativo, adotando pressupostos que identificam a puérpera, o recém-nascido e a família como um 'outro' envolvido em excepcionalidades, assim como a necessidade de particularização da assistência. Além disso, o tempo narrativo é evocado por meio de performances lúdicas, utilização de linguagem não verbal e o exercício cotidiano da "paciência".

ABSTRACT: This is a study of a qualitative nature, with the objective to comprehend the network of symbols and significances expressed by nurses and families living through the narrative period in a multiplepatient recovery room of the Maternity Ward in a public hospital. The theoretical support for this study is founded on anthropological studies that utilize narrative therapies in data collection and interpretation. In order to collect the data, participative observation techniques and ethnographic interviews were applied. The process of categorizing and analyzing the data was based upon Ethno-nursing. The principle results indicate that within the context of this investigation, workers seek the transformation of the clinical period into the narrative period, adopting suppositions that identify with the woman who has given birth, the newborn, and the family as an "other" - involved with exceptions. They also identify with the need to individualize their care. Beyond that, the narrative period is evoked through lucid performances, use of non-verbal communication, and the daily exercise of "patience".

RESUMEN: Investigación de naturaleza cualitativa, tuvo por objetivo comprender la red de los símbolos y los significados manifestados en la vivencia del tiempo narrativo entre las trabajadoras de Enfermería y las familias en un servicio de Alojamiento Conjunto de una Maternidad Pública. El soporte teórico fue con base en los estudios antropológicos que utilizan las narrativas terapéuticas para la colecta y la interpretación de los datos de la investigación. Para la recolección de los datos se utilizaron las técnicas de la observación participante y la entrevista etnográfica. El proceso de categorización y del análisis de los datos se construyó basado en la Etno-enfermería. Los resultados principales señalan que, en el contexto investigado, las trabajadoras actuan buscando la transformación del tiempo clínico en el tiempo narrativo, adoptando presupuestos que identifican a la puérpera, al recién nacido y a la familia como un "otro", envueltos estos con sus excepciones, así también, la necesidad de una particularidad y/o peculiaridad en la asistencia. Además de esto, el tiempo narrativo es invocado mediante las performances lúdicas, la utilización de un lenguaje no verbal y a través del ejercicio cotidiano de la "paciencia".
Endereço:

Marisa Monticelli

R. Duarte Schutel, 181, Torre II, Apto 1326

88015-640 - Centro, Florianópolis, SC

E-mail: marisa@nfr.ufsc.br
Artigo original: Pesquisa

Recebido em: 15 de outubro de 2004

Aprovação final: 15 de março de 2005 


\section{INTRODUÇÃO}

O cenário hospitalar tem sido considerado como um ambiente poderosamente restritivo em termos de troca de experiências, negociação de saberes, práticas educativas dialógicas, relações horizontais de poder, e para a permanente troca que deveria acontecer entre as esferas do viver social e do viver institucional. Estas restrições estão pontuadas de modo mais ou menos intenso na grande maioria dos hospitais, considerados "instituições totais", que funcionam como barreiras utilitárias ou simbólicas ameaçando possíveis crescimentos mútuos, tanto dos profissionais, como dos clientes.

A racionalização dos valores biomédicos e da estrutura autoritária é internalizada pelos trabalhadores institucionais e pode ser percebida, nas relações entre profissionais e clientes, através da burocracia do cuidado $^{2}$. Tal burocracia está presa às normas, às regras institucionais e à cultura da competência biomédica que leva a que o tempo clínico seja expressado em termos pragmáticos, em detrimento das experiências humanas envolvidas no processo terapêutico.

Nos estudos antropológicos que utilizam como base teórica as narrativas terapêuticas ${ }^{3}$, o mundo do hospital opera em dois tempos, sendo que quase sempre e na maioria das vezes, o primeiro sobrepuja o segundo. O tempo clínico é considerado pragmático, baseado em evidências, em protocolos, na objetividade, na competência em descobrir fatos que auxiliem no diagnóstico e tratamento, bem como na inflexibilidade das rotinas. É o tempo da rapidez e da eficácia, paradigmaticamente expresso no tempo do médico e de alguns outros trabalhadores do hospital que precisam dar conta das tarefas a serem desenvolvidas, no 'menor tempo possível', uma vez que o tempo custa caro.

O tempo narrativo, por sua vez, é o tempo que toma lugar num espaço altamente transacional no qual as condutas de ambas as partes são determinadas por expectativas de socialização e de reconhecimento pelas individualidades e subjetividades. Esse tempo é o tempo humano das pessoas internadas, dos clientes, mas também, em algumas situações e contextos, de alguns profissionais de enfermagem que enfatizam o lado metafórico e fenomenológico do cuidado em saúde, "examinando as interações clínicas como transações entre o mundo da biomedicina e o mundo da vida dos pacientes" $3: 20$.

As observações, análises e estudos já realizados, focalizando esse assunto em ambiente hospitalar, têm revelado, em sua maioria, que o tempo das trabalhadoras de enfermagem, no contato com os clientes e suas famílias, está impregnado pelo tempo objetivado no relógio, o tempo cotidiano, o tempo das rotinas de trabalho propriamente ditas e que pouco acrescentam para o fortalecimento das relações terapêuticas. Contrariamente, nossa convivência com algumas trabalhadoras que atuam em Maternidades, por meio da observação criteriosa 'por cima dos ombros' das condutas cotidianas não criativas, fez-nos perceber também diferentes perspectivas de temporalidade, manifestadas tanto por expressões verbais quanto não verbais, durante a interface cuidativa entre trabalhadoras de enfermagem, puérperas, recém-nascidos e famílias que vivenciam o período pós-parto em cenário clínico, entendido como o espaço simbólico de interações, poderes e saberes envolvidos nos processos terapêuticos do cuidar em enfermagem² ${ }^{2}$.

Diante desta constatação, o olhar interrogativo dirigiu-se para o desenvolvimento de um estudo de doutoramento, cujo recorte apresentamos neste artigo. A tese propriamente dita envolveu uma ampla etnografia, cujo trabalho de campo, em uma unidade de Alojamento Conjunto, teve a duração de um ano. Neste recorte da tese apresentamos alguns dados etnográficos, resultados e análise relativos à pergunta de pesquisa: como se dá a construção do tempo narrativo entre trabalhadoras de enfermagem e famílias no cenário clínico do Alojamento Conjunto?, cujo objetivo é o de compreender a rede de símbolos e significados expressa na vivência do tempo narrativo entre a enfermagem e as famílias durante o período institucional pós-natal. Acreditamos que, ao compreendermos tal rede de símbolos e significados impressa nos processos terapêuticos do cuidar em enfermagem, teremos a oportunidade de refletir sobre essa realidade clínica e, ao mesmo tempo, propormos alternativas de superação do tempo restritivo, objetivado apenas no suprimento das necessidades corporais das puérperas e dos recém-nascidos.

Nesta investigação, adotar a perspectiva do Alojamento Conjunto como uma realidade clínica, significa reconhecer que os processos terapêuticos do cuidado são fenômenos culturalmente construídos e interpretados e que, neste jogo de reconhecimento, tanto a cultura profissional quanto a cultura familiar possuem espaços de articulação e de movimentos, ainda que as rotinas e as regras institucionais desenhem os contornos normativos da assistência. 


\section{METODOLOGIA}

Realizou-se uma etnografia, adotando-se a observação participante como técnica de coleta de dados principal e a entrevista etnográfica como técnica complementar no levantamento de dados ${ }^{4-5}$. O trabalho de campo foi desenvolvido em unidade coletiva de Alojamento Conjunto de uma Maternidade pública do sul do Brasil, considerada como a 'realidade clínica' onde acontece o cuidado pós-natal imediato. O período de coleta de dados ocorreu entre março de 2001 e março de 2002. Os sujeitos do estudo foram 19 trabalhadoras de enfermagem e 42 membros das famílias, selecionados como informantes-chave, de modo proposital e intencional, por terem mais conhecimento sobre o assunto sob investigação e por contribuírem de modo mais eficaz para a consecução do rigor da pesquisa ${ }^{4}$.

Durante o período de observação, selecionamos como focos de atenção todas as atividades relacionadas ao que trabalhadoras e famílias diziam e faziam em conjunto " enquanto vivência coletiva do cuidado terapêutico no Alojamento ", sem descuidarmos destes mesmos elementos no que diz respeito às interações entre as profissionais de enfermagem, entre estas e os outros profissionais do setor e o que ocorria no interior de cada família e ainda as relações interfamiliares. As entrevistas complementares foram realizadas com os membros das famílias e com as trabalhadoras de enfermagem, sempre no sentido de aprofundar, polir, aperfeiçoar ou descartar as interpretações feitas pela pesquisadora durante o trabalho de observação. Estas sempre foram previamente agendadas com os informantes, respeitando seus direitos, inclusive com relação aos horários de início e término, e no que diz respeito ao indiscutível direito de não participação.

O plano de organização e análise dos dados foi feita a partir do método da Etnoenfermagem ${ }^{4}$, sumarizado pelas seguintes etapa: coleta, descrição e documentação dos dados brutos; identificação dos descritores e componentes; identificação de padrões recorrentes; e formulação de achados relevantes. Mantivemos perene preocupação com o rigor científico do estudo em todas as etapas de coleta e análise dos dados, utilizando os critérios de credibilidade, confirmabilidade, saturação e transferibilidade ${ }^{6}$.

Quanto aos aspectos éticos, todas as atividades de pesquisa foram balizadas pelos princípios da beneficência, não maleficência, justiça e autonomia, abordados na Resolução específica do Conselho Nacional de Saúde e os princípios do Código de Ética Profissional Brasileiro. O projeto de pesquisa obteve consentimento formal da instituição hospitalar onde a mesma foi desenvolvida, além de ter sido submetido ao parecer do Comitê de Ética em Pesquisa da Universidade Federal de Santa Catarina. A identificação da instituição foi resguardada e a dos informantes (da enfermagem e das famílias) também manteve-se em sigilo, adotando-se nomes fictícios. Como meio de realçar a privacidade pessoal dos membros da equipe e das famílias obteve-se consentimento livre e esclarecido de todos os informantes.

\section{RESULTADOS E DISCUSSÃO}

\section{O tempo do 'outro' como excepcionalidade}

É possível perceber que, para as trabalhadoras, o tempo narrativo ganha contornos de excepcionalidade, de vivência extraordinária. Um tempo que, ao invés de afastar, de objetivar, de 'fazer tudo rápido', entra em suspensão com o tempo cotidiano do 'todo dia a mesma coisa' e inaugura um modo diferente de olhar para o 'outro', pois trata-se de um 'outro' (puérpera, família, recém-nascido) que, subjetivamente, vive o seu tempo, o seu nascimento, a sua experiência. Ambos (trabalhadoras e 'clientes') inauguram um novo tempo de relações e aproximações terapêuticas. Uma situação observada no campo, mostra como o tempo clínico é transformado em tempo narrativo:

a puérpera [que expressa sérias dificuldades para amamentar o recém-nascido] aperta um pouco o mamilo e o leite esguicha no rosto da criança. Ela acorda e a mãe ri. Zulmira [auxiliar de enfermagem] ajuda a posicionar o bebê, colocandoo barriga com barriga. O bebê abre um pouco a boca e a mãe abre também a sua. Zulmira diz para que ela tenha calma e espere o bebê sentir o gosto do leite. Repentinamente a criança faz. um barulho com os lábios, revelando que a sucção já estava começando. A mãe ri novamente, parecendo interagir muito positivamente com o filho. O quadro que se apresenta já é bastante diferente de quando entramos, quando mãe e filho pareciam estar distantes. A auxiliar di . para que a puérpera conserve o bebê bem próximo do seu corpo e ofereça o seio.

Auxiliar: deixa ele pertinho de onde estava...ele precisa se acostumar com o ambiente [...] isso[...] deixa ele sugar. Vocês estão comecando a se conhecer. Olha só como pega bem. Deixa ele mamar o quanto quiser[...] tás te sentindo bem?

Puérpera: bum, hum (absolutamente concentrada na sucção do filho) (Extratos do Diário de Campo - situação vivenciada 
após 40 minutos de contato entre a trabalbadora, a puérpera e o recém-nascido).

O tempo narrativo é menos linear que o 'tempo do relógio' e, independente da duração ou da freqüência com que estas trabalhadoras interagem com as puérperas e suas famílias, observa-se que as tarefas não se encontram ali, somente para serem cumpridas. As trabalhadoras criam alternativas e se envolvem com as clientes de modo que o tempo passado em conjunto seja realmente significativo para ambas. O depoimento da puérpera Eliane, relatado algumas horas após o terceiro encontro com a atendente Lia (para tratar de uma retração mamilar que dificultava imensamente a amamentação), proporciona um exemplo desta intenção:

pesquisadora: como vocêpercebe o cuidado que a Lia teve com você e com o bebê??

Puérpera Eliane: ah, eu acho assim que é a atenção que ela dá, né, que não são todas as que faz̧em isso. Eu tinha ido ali num outro setor e não deram aquela mesma atenção pra mim né? Ela já teve ali no quarto ontem comigo e eu vi também a maneira como ela acata as mães. Ela diz: "vem cá que eu vou te ajudar; tens que ter paciência". Ela não faz a gente se sentir assim desprotegida, desamparada. Ela ampara, ela protege, gostei, gostei mesmo. É diferente. Tem gente aqui que não dá a mesma atenção, né? A gente é mãe de primeira viagem, é meio despreparada $[. .$.$] não sabe o que vai enfrentar, [...] mas ela te$ prende [...] aquilo vai te envolvendo, tu vais entrando naquela conversa porque faz bem pra ti, né? Te deixa confortável, segura, confiante que vai dar certo, apesar da dor, das dificuldades que a gente tá passando ali, né?

Pesquisadora: o que você estava sentindo em relação à amamentação do teu neném?

Puérpera Eliane: antes dela chegar? [assinalo que sim] ah, insegura, com medo né? Mas eu tava com meeeedo mesmo! Tinha o mamilo meio plano, encheram ele [o bebê] de copinho, ele só dormia, en tava horrivel, quase desistindo[...] medo que ele não fosse pegar. A vontade da gente é de abandonar tudo. Ah, mas quando ela chegou e comecou a falar, ontem, en já vi que tinha uma coisa boa pela frente[...] me tratou assim com aquela paciência que ela tem. Insistindo comigo: "vai pegar, tenha fé, vai pegar" [...] eu achei bom. É uma pessoa paciente, uma pessoa que tá assim pronta pra ajudar. Tem muito cuidado com o nenê,, pega de mansinho, não levanta aos trambolhões. É uma pessoa que não mede esforços. Pode tar cheia de trabalho pra fazer, mas quando chega uma mãe lá ela dá atenção. Vai, te ajuda, te ouve.

A avaliação feita pela puérpera é reveladora de que o tempo humano pode ultrapassar o tempo clínico. Ainda que a ação da trabalhadora tivesse que responder ao problema físico apresentado naquele mo- mento por Eliane, e por extensão, ao seu filho recémnascido, o cuidado terapêutico não se limitou às manobras de exteriorização do mamilo. Vários outros sinais apontados pela puérpera, como a atenção recebi$d a$, seja por ela ou a atenção que ela presenciou quando do encontro com as outras colegas de quarto, os sentimentos de amparo, proteção, confiança, conforto e segurança fazem emergir outros significados para a situação vivenciada.

Lia, na interação terapêutica apresentada, utilizase de movimentos persuasivos para incluir a puérpera na produção de significados e não apenas como uma paciente que tem um mero corpo a ser manipulado para que possa satisfazer aos desejos do filho. A percepção de Eliane que a trabalhadora a envolve e faz com que vá entrando na conversa e também o fato de mostrar que tem uma coisa boa pela frente leva a crer que, de alguma forma, a puérpera se entregue aos seus cuidados. Mas isto não é feito de modo 'natural', somente porque trata-se de uma profissional de saúde e que, por isto, deve saber o que está fazendo. A puérpera faz escolhas, avalia, acata o cuidado (apesar da dor) porque este cuidado é diferenciado, "centrado no ator, menos do que centrado na doença" 3:92. Assim, o jogo interativo entre as duas é marcado. Eliane não apenas faz ou executa os procedimentos indicados, mas estrutura suas ações e segue os ensinamentos, em resposta ao tempo narrativo engendrado pela trabalhadora: pode estar cheia de trabalbo pra fazer, mas quando chega uma mãe, ela dá atenção. Vai, te ajuda, te ouve.

\section{O cuidado "não deve ser uma Salve-Rainha, a mesma oração para todos"}

A observação feita pela técnica de enfermagem Mirtes pode ser considerada como uma síntese representativa da necessidade de particularização da assistência:

acho que a gente deve apoiar, cuidar das mulheres e dos recém-nascidos que são nossos clientes aqui, mas isto deve ser feito de modo particular, com cada um, com cada família [...] dar atenção especial. Não acredito, mas não acredito mesmo na mesma coisa pra todo mundo[...] a mesma Salve-Rainha! (Extratos de Entrevista).

Zulmira, ratificando o pensamento da colega, acrescenta que não adianta rezar a mesma oração; cada um é $u m$. E respondendo à pergunta da pesquisadora sobre como é possível descobrir as peculiaridades de cada um - num local em que outras trabalhadoras queixam-se intermitentemente sobre a sobrecarga de tra- 
balho - verbaliza de modo desconcertante: tem que afinar o ouvido! A trabalhadora Lia faz coro, adicionando: é só prestar atenção. Se a gente faz, isto de modo consciente, vai ver que cada um é diferente e enfrenta de modo diferente a situação.

Efetivamente, a prática diária destas trabalhadoras mostra que não há incoerência entre o que dizem e o que fazem, haja vista os registros que realizamos em distintos momentos de interação terapêutica, onde havia a demonstração explícita de que quando a trabalhadora estava interagindo com os participantes, ela estava 'inteira' com eles.

As trabalhadoras que atuam sob esta perspectiva, nos encontros clínicos, possuem reconhecimento que não deve haver apenas um modelo a ser seguido. A “Salve-Rainha” deve dar lugar a 'orações' singulares, espontâneas, que surgem do encontro autêntico entre trabalhadoras e mulheres. As necessidades podem dar a falsa impressão que são repetidas, mas a ação clínica é diferenciada, específica para cada cenário e para cada participante:

[...] pra cada mãe tem um caso e uma palavra [...] os sentimentos delas são diferentes e eu cuido muito disso. A gente tem cinco dedos nas mãos. Todos são dedos, mas não são iguais. Assim são as pessoas (atendente Lia - Extratos de Entrevista).

Estes dias tinha uma [puérpera] que não tinha jeito de se acalmar. Estava muito nervosa e o leite não descia. Descobri que ela gostava de música e que, durante a gestação, quando o nenê tava muito agitado, botava uma música bem suave para ouvir. Pedi pro pai trazer o CD da música e um aparelho. Depois de algum tempo, a mãe já tava bem mais calma e o leite descendo, descendo. A criança teve alta mamando[...] Entendes? Devem estar ouvindo a música até hoje [...] [risadas]. Então é assim: tem mãe que não gosta de música, mas gosta de contar bistórias pro filho. Tem outras que cantam. Tem outras que ficam em silêncio, tem outras que só dão de mamar em pé. Precisa entender a necessidade de cada uma (auxiliar Zulmira. Extratos de Entrevista).

Como as teóricas da Enfermagem têm debatido, por décadas, um dos principais elementos da sistematização da assistência é, justamente, a individualização do cuidado. Apesar desta sustentação, a prática demonstra que ainda há um imenso hiato entre o que se propõe e o que se realiza. Entretanto, algumas práticas observadas no Alojamento apontam para a inseparabilidade entre individualização e cuidado terapêutico. Este caráter relacional leva as trabalhadoras a reconhecerem que um novo 'paciente' em uma nova situação, não é uma réplica de outros 'pacientes' em situações semelhantes. Elas talvez consigam aquilo que tanto evocamos quando falamos profissionalmente em 'cuidar da pessoa' e não somente da 'doença que a pessoa tem'.

A individualização da assistência está subsumida na percepção de alteridade, de heterogeneidade, de diversidade. O cuidado requer que se olhe para os clientes 'vendo' neles diferentes representações e múltiplas nuanças, sejam idiossincráticas ou derivações sócio-culturais diversas. Isto envolve, por exemplo, não fazer pré-julgamentos ou ter pré-conceitos sobre determinados clientes ou situações clínicas. Em todas as relações terapêuticas das quais fomos testemunhas, não observamos comportamentos estereotipados ou discriminatórios do tipo: não é uma boa mãe; não é uma boa paciente; é egoísta, nunca pensa na criança, tão comuns em outras situações assistenciais ou mesmo em outros cenários cuidativos como em algumas Maternidades americanas ${ }^{8}$.

A individualização da assistência também envolve considerar os sujeitos participantes dos cuidados pósnatais - principalmente as mulheres puérperas - como seres culturais. Embora raramente verbalizem o termo deste modo, essas trabalhadoras atuam com a representação de que o puerpério e a própria maternidade, ainda que sendo eventos que se localizam no corpo, não são apenas indícios do desempenho de uma atividade biológica, ou seja, natural. Constituemse, também, em eventos culturais, ou seja, "são submetidos a uma construção simbólica que se impõem aos indivíduos"9:33. Vislumbrando-se o objeto desse estudo, isto contribui para assegurar que a possibilidade de transformação do tempo clínico em tempo narrativo contribui para que os co-participantes do processo terapêutico sejam levados a "construírem objetos de atenção terapêutica que são históricos, temporais e repletos de dimensões sociais" ${ }^{\text {10:51. }}$.

O processo de individualização da assistência envolve ainda considerar as variações e interpretações idiossincráticas das mulheres puérperas. Tal consideração passa pela compreensão de que as sensações corporais não são unívocas e que a interpretação das puérperas sobre tais sensações (a dor, por exemplo) está atrelada tanto ao sistema de crenças, como a sensações subjetivas e culturais sobre a imagem corpo$\mathrm{ral}^{11}$, em que a vivência da dor pode estar relacionada a expectativas e graus de ansiedade pessoais, ao código social e uma miríade de experiências que as mulheres vivenciaram em momentos anteriores. Para as trabalhadoras, a mulher puérpera traz para a experiência do Alojamento, inúmeras peculiaridades fisiológicas, sociais e psicológicas que precisam ser consideradas. 
É muito importante ressaltar que a necessidade de individualização da assistência não é percebida somente pelas agentes de enfermagem que desenvolvem esse modo de cuidar, mas ela é considerada essencial, de igual modo, pelas próprias puérperas que são envolvidas nos encontros clínicos. A assistência particularizada é uma condição 'sine qua non' da interação terapêutica, como assinalou a puérpera Carolina, dizendo que se sentia como única quando estava sendo cuidada, ou como refere a puérpera Eliane, no seguinte depoimento:

pesquisadora: [...] você falou que ela [a trabalhadora com quem interagiu] é diferente. Podes me dizer por que?

Puérpera: ah, é que eu comparo com as outras, né? Eu acho que elas podiam ser mais assim...não digo atenciosas, mas assim mais, como é que eu vou explicar...en acho que não dá atenção pro bebê, merecida naquela hora. Só tá ali porque tem que estar. Dá o banho, troca, deu... mãe vem ver isso, mãe vem ver aquilo...então não tem aquela troca de carinho, parece que todo mundo é igual. Fazem tudo da mesma maneira. Tem umas até que são mais atenciosas mas eu não sei, pode ser que tenha sido só comigo, né? Deu um banho muito ligeirinho. Eu não consegui nem ver direito. Meu Deus, é meu primeiro filho...eu quero aprender! (Extratos de Entrevista).

Em resumo, ao interpretarem que o cuidado não deve ser a mesma "Salve-Rainha" para todas as mulheres, as trabalhadoras revigoram a noção de significado, qual seja, a de que não existe significado no vazio $^{5}$; um significado é sempre significado 'para' alguém. Assim, estas trabalhadoras nos ensinam que o nascimento, o sofrimento a ele associado, as representações sobre o corpo puerperal, as exigências e necessidades de aprendizagem, dentre outros, são processos intersubjetivos e interpretativos que só adquirem sentido e possibilidade de transformação (sim, porque a aprendizagem sempre envolve transformação), na individualização da assistência.

\section{A ludicidade como estratégia para superação da linearidade temporal}

Sempre que a situação permite, as trabalhadoras relacionam-se com as puérperas e suas famílias de modo lúdico, incentivando-as a adotarem perspectivas menos dolorosas para a experiência e conduzindo-as à exploração de atitudes até mesmo prazerosas frente às dificuldades. Percebe-se que os participantes 'entram no clima' provocado pelas trabalhadoras e respondem de modo conotativo à experiência conjunta. Neste exercício, novas experiências vêm à tona, o que reforça o cuidado expressivo traduzido no tempo narrativos.
A ludicidade gerada, em clima de companheirismo e confiança, contribui para induzir os participantes ao relaxamento e diminuição da ansiedade, tão freqüentes no período de internação pósnatal, primordialmente quando a puérpera ou a criança estão envolvidos em patologias ou em processos dolorosos. Algumas vezes as trabalhadoras utilizamse de ações lúdicas ou de pequenas brincadeiras logo no início do encontro, com a visível intenção de 'quebrar o gelo', como a referência espirituosa que a auxiliar de enfermagem fez, utilizando-se dos nomes similares de Júlio (o pai adolescente de um recém-nascido portador de lábio leporino) e Júlia (a mãe adolescente, puérpera), ao que o pai da criança adicionou: é quase uma dupla sertaneja, ou ainda quando a trabalhadora propõe que pai, mãe e filho 'fiquem' à três (adotando o termo 'ficar', utilizado pelo próprio casal de adolescentes, tentando desfocar um pouco a atenção e dando chances para que ambos pudessem relaxar um pouco, diante da difícil situação). Num momento em que as tensões estão à flor da pele e que a família sente dificuldades para caminhar com as próprias pernas, os sorrisos abrandam a situação e desarmam as defesas que poderiam estar presentes no início da interação com as profissionais.

Noutras vezes, as ações lúdicas provocadas intencionalmente pelas trabalhadoras são utilizadas quando encontros clínicos estão em pleno curso, numa tentativa de levar os participantes a suplantarem as sensações de mal-estar ou manifestações dolorosas. Isto pode ser observado quando a puérpera queixa-se das mamas cheias, desconfortáveis e prestes à empedrar, dizendo que tem leite para a criançada toda da maternidade e Mirtes aproveita o breve intervalo de relaxamento para introduzir a possibilidade de 'levar à sério' o desejo da puérpera, convidando-a para ser doadora de leite. Ato voluntário, aliás, que continuou durante quatro meses, após a alta da puérpera e do recém-nascido. Portanto, ajudar a transitar com mais leveza pelo caminho da dor e do desconforto (ingurgitamento mamário, neste caso), não elimina o sofrimento, mas pode trazer à prática da enfermagem um caráter mais lúdico que leve os co-participantes a perceberem, inclusive, a possibilidade de alguns benefícios antes não vislumbrados (como a doação do leite em excesso).

Tais ações não são observadas na vida ordinária da clínica e somente tomam dimensões 'adicionais' como as puérperas que tomaram coragem para provar o próprio leite - quando incentivadas pelo 'oxigênio extraordinário' das palavras da trabalhadora. Isto nos mostra que "o lúdico é a marca do ato criador, 
que numa modernidade embrutecedora e repetitiva, atrofiou-se pelo desuso"12:14.

Tais condutas diminuem a pressão no ambiente, criando um clima propício para investigações necessárias à solução de problemas ${ }^{13-14}$. Assim, sorrir, provocar o riso e 'desarmar' os medos levam as pessoas a se tornarem mais flexíveis e a buscarem alternativas de ação, contribuindo para que o tempo clínico seja revertido em tempo narrativo.

\section{A gestualidade que acolhe a experiência vivenciada}

Do mesmo modo que usam atos lúdicos, as trabalhadoras também utilizam-se da linguagem não verbal para transformar o tempo clínico em tempo narrativo. Uma pequena amostra desses tempos corporais simultâneos de ação, movimento e interpretação pode ser evocada, a partir de uma ação terapêutica desenvolvida pela técnica de enfermagem Mirtes.

Sua atividade requer que se agache o tempo todo uma vez. que as puérperas, quase sempre, amamentam seus filhos sentadas nas cadeiras brancas de plástico disponiveis nos quartos. Para ficar no mesmo nivel da puérpera e da criança, a trabalhadora precisa ficar quase de joelhos, movimentando-se para todos os lados, como que "cercando" o binômio. Percebo também que tem outras puérperas que se aproximam da atividade, querendo olhar [... Tparecem gostar do que vêem (Extratos do Diário de Campo).

Os gestos utilizados pela trabalhadora são suaves, de respeito ao outro e de consideração às peculiaridades da mulher e do recém-nascido. As expressões corporais como a proximidade física, o sorriso e $\mathrm{o}$ ar de disponibilidade que faz questão de demonstrar transmitem confiança e segurança à puérpera e à pequena platéia que assiste à cena. Tais expressões mostram, igualmente, que o diálogo não evoca apenas uma forma de falar, ou um discurso textual em que ambas as partes, muitas vezes têm dificuldades em se reconhecerem; mas é também percebido como um modo de atuar dinâmico e dinamizador "que se encontra subjacente na performance (ação) clínica" 3:29.

Suas atitudes/gestos/expressões distinguem-se daqueles usados em situações semelhantes, por outras trabalhadoras. Não são gestos mecânicos, mas assemelham-se a uma dança; um movimento performático onde a estética é um valor percebido. Uma dança em que todos os participantes se envolvem e são envolvidos. Uma dança cujo ritmo é marcado por condutas instrumentais, mas também por condutas expressivas que evocam os sentidos experienciais de ouvir, provar, cheirar, ver e tocar.
Manter os olhos no mesmo nível ou ficar facea-face com a puérpera ou com os demais membros da família que participam do cuidado é considerado por estas trabalhadoras como uma ferramenta indispensável que estimula a comunicação interacional. Outro exemplo pode ser adicionado:

pesquisadora: en percebi que você falava com ela [puérpera], procurando ficar face-a-face [...]

Zulmira: ah, eu faço isto sempre[...] nunca fico de pé. Procuro ficar na mesma altura. Acho que é uma questão de respeito à paciente. Não sou superior. Estou ali como ajudante, assessorando na amamentação. Mas se eu não ficar no mesmo nivel que ela, en já mostro que estou com pressa ou então que vou apenas dar uma olhadinha (Extratos de Entrevista).

A linguagem não verbal, como a permanência dos 'olhos nos olhos' durante a interação, parece inaugurar outro tempo que colabora para a interpretação de que é possivel ir além do 'tempo do relógio'. A interação face-a-face é algo utilizado com freqüência e de modo consciente por Zulmira que vê nesta ação uma atitude de respeito que promove a dialogicidade, num momento em que 'ninguém é superior a ninguém'; o papel da trabalhadora não é o de professor-aluno, mas o de parceiro. O estar face-a-face também provoca um instante de parada, de ponto morto entre o agito e a quietude necessária. Zulmira admite inequivocamente que, na narrativa terapêutica, o instituído precisa ser subvertido e dar lugar ao vivido.

Do mesmo modo, o silêncio é utilizado como uma linguagem não verbal que faz efeito na performance clínica (algo virtualmente não muito valorizado em outros contextos). Inúmeras vezes observamos que o silêncio 'provocado' pela trabalhadora era utilizado como ação terapêutica, principalmente quando esta, literalmente, dava um tempo para a puérpera ou a familia aprender ou para se recobrar do sofrimento. Algo que, no tempo clínico, é quase desvalorizado.

O uso do silêncio, muitas vezes é traduzido, na prática, pelos verbos ouvir, dar atenção ou deixar chorar.

Ela chora um monte contigo ali e a gente vai ouvindo, vai aconselhando, vai dando segurança...isto ai tu sabes que é o segredo da enfermagem, né? Tens que ouvir, dar atenção...não adianta ir tocando logo e ver como tá a mama. Tens que ouvir a mulher. Deixar ela expressar as inseguranças [...]. O mundo não é só mama, né? Daí, depois que ela chora um monte, ela passa a descer o leite que não descia. Isto tu podes fažer até experiência mesmo. Depois que ela desabafa com a gente parece que abre tudo (técnica Alda - Extratos do Diário de Campo).

A trabalhadora interpreta que o silêncio, ativamente incorporado na ação de ouvir, é uma ferramen- 
ta indispensável que a enfermagem utiliza para cuidar, sendo este um de seus 'segredos'. Talvez por consistir num 'segredo', a habilidade em utilizá-lo deve ser a mais fina possível. Como diz a técnica de enfermagem Alda, tem que afinar o owvido. $\mathrm{O}$ uso do silêncio é reconhecido como uma arte, mais do que uma técnica propriamente dita, onde 'não ter palavras' tem maior repercussão terapêutica do que falar em alto e bom som; do pedestal de quem sabe mais do tempo clínico do que aquele que compreende mais do tempo humano.

Essas trabalhadoras sabem que a exploração de tais instrumentos, na aproximação com as puérperas e suas famílias, pode levá-las a uma outra qualidade de cuidado, sem reduzir os significados necessários à atenção aos problemas orgânicos das mulheres e dos recém-nascidos. Portanto, aquilo que não é dito ou aquilo que é menos dito, também ajuda na construção do tempo narrativo.

Outra ação não verbal que permeia os encontros refere-se ao uso do toque; talvez a conduta silenciosa que maior reflexo apresente durante as transações efetuadas. Há uma concordância explícita de ambas as partes de que o toque gentil e afetuoso faz a diferença no cuidado do Alojamento Conjunto:

[...] ela me chamou pelo nome, não foi logo botando as mãos nas mamas da Júlia. Ela se preocupou com a gente, né? Até comigo. É gente fina mesmo! (Pai Júlio - Extratos de Entrevista).

Técnica Janaina: vamos lá, não precisa ter pressa. Relaxe um pouco (toca nos ombros da puérpera). Nossa, como este músculo está tenso! Fecha um pouquinho os olhos e solta os ombros. Isso! Agora sim. Vamos recomeşar? (Extratos do Diário de Campo).

Depois de uma hora de interação, a técnica ajeita a criança sobre o travesseiro, posiciona as mãos da puérpera, uma sobre as nádegas do bebê e outra sustentando a cabeça. Ela faz. com que o seio da mãe toque de leve os lábios da criança. Quando esta abre a boca, introdu zentilmente o mamilo e a aréola mamária. O bebê, sem abrir os olhos, abocanha a mama e inicia movimentos vigorosos de sucção. A puérpera sorri, olhando para a criança (Extratos do Diário de Campo).

O toque físico utilizado não deixa dúvidas de que são as mulheres puérperas as detentoras do poder sobre seus corpos. Os exemplos anteriores mostram que as trabalhadoras solicitam que as próprias puérperas façam a expressão de suas mamas ou então solicitam permissão para tocá-las. As trabalhadoras que constróem o tempo narrativo não se apossam do seio materno, apenas acenam uma ação para indicar o caminho; não invadem privacidade da mulher e da fa- mília, ao contrário dos gestos comuns de outros profissionais do Alojamento que 'manipulam' as mamas das puérperas como se fossem suas.

O toque físico ao recém-nascido também é usado de modo terapêutico pelas trabalhadoras. Em muitas situações observadas, a criança é tocada gentilmente e com a merecida recepção para quem está chegando no mundo. Freqüentemente os bebês são acariciados e individualizados pelo toque. Um recorte peculiar desta situação foi demonstrado, por exemplo, na interação que a técnica de enfermagem Janaína promoveu com a criança portadora de lábio leporino. As condutas utilizadas como: segurar o bebê junto ao peito; abraçá-lo; passar as mãos em seu rosto e cabelos; transportá-lo no colo e não no berço; falar com ele sorrindo, olhando fixamente em sua face; colocálo estrategicamente na frente dos pais, de modo que o rosto do recém-nascido ficasse na mesma altura deles, bem como estimular a linguagem não verbal do pai do bebê, como segurá-lo ao colo e fazer carinho nos pés durante a amamentação, demonstram que a criança é acolhida e bem recebida.

Há que se perceber que estes gestos não são apenas terapêuticos porque auxiliam na transposição de uma situação em que a mulher não amamenta, para aquela em que ela se põem a amamentar, mas tomam contornos ainda mais apropriados, se considerarmos que é um bebê que tem poucas horas de vida e cujos pais ainda apresentam dificuldades para superar o trauma de dar à luz um a filho com mal-formação. As ações da atendente carregam uma mensagem de afeição e, de modo mais importante, de aceitação, numa situação socialmente estigmatizante. A trabalhadora literalmente e figurativamente 'abraça' a família. Ao sorrir enquanto encara o bebê, ela convence a família de que não tem repulsa ou sentimentos discriminatórios em razão de sua aparência distinta. Novamente o tempo clínico é superado pelo tempo humano.

\section{A "paciência" como ingrediente do tempo narrativo}

Além da ludicidade e da utilização da linguagem não verbal, as trabalhadoras revelam que "ter paciência" é, de igual modo, um dos ingredientes do caldo terapêutico do tempo narrativo:

quando a puérpera está com o seio ingurgitado ou o colostro ainda não desceu ou não tem bico [...], normalmente na primeira vez ela [a criança] não pega. Ai tem que ir a primeira, segunda, terceira vez, pra ela aprender. Tem que ter paciência e ela também. Tu viste aquela de ontem, né? Já era a segunda veze depois 
eu ainda fiquei com ela outras vezes. Não é assim de uma hora para outra [....] (auxiliar Lia - Extratos de Entrevista).

O casal de fora [da maternidade] veio e passon alguns dias vindo aqui. Ali comecou um trabalho. Ela [a puérpera externa] estava fissurada, mama cheia, estava no terceiro dia e é o momento mais dificil da amamentação...o terceiro ou quarto dia [...] inchaço [...] edema [...] esta é a pior parte da amamentação, nem é a fissura. O inchaço do terceiro on quarto dia, porque tu tiras e daqui a pouco já está inchado outra vez. [...] a paciente as vezes faz, faz, e não vê evolução. Precisamos ter muita paciência e ela também. O alivio imediato é um pouco falso como eu costumo dizer porque tira um pouquinho e quando tu vês a outra já está cheia (técnica Mirtes - Extratos de Entrevista).

Tudo bem, tudo bem, vamos manter a calma. Não vamos fazer nada que você não queira. Eu estou aqui para te ajudar e não para te fazer sofrer [...] pode contar comigo. Quem sabe nós deixamos para mais tarde? Também podemos deixar para trabalhar amanhã de manhã (técnica Simone - Extratos do Diário de Campo - situação em que a trabalhadora interage com a puérpera que refere pavor em tocar o coto umbilical durante a aprendizagem da antissepsia).

Ali comecou um trabalho ou vamos continuar trabalhando amanhã dá a dimensão do tempo humano que precisa ser efetivamente considerado. Novamente aqui o tempo do relógio contrasta com o tempo narrativo, uma vez que a trabalhadora não é apenas uma executora das atividades previamente estabelecidas, mas é autora de seu próprio tempo com os clientes. Isto não significa que as trabalhadoras andem na contramão, ou que não cumpram com as tarefas do dia ou do turno de trabalho. Também não significa que não tenham pressa ou tenham outros entendimentos acerca da responsabilidade profissional; "ter paciência" alude muito mais ao tempo que permanecem por inteiro com as mulheres, os recém-nascidos e as famílias, atentas ao ritmo de cada um. O resultado concreto do tempo de cada um é percebido no depoimento das próprias beneficiárias do cuidado: ferente'?

pesquisadora: porque vocês dizem que a consideram 'di-

Puérpera Marilia: ela é simpática, senta na frente da gente, presta atenção na gente [...] (os olhos se enchem de lágrimas).

Puérpera Carolina: eu acho que ela não compara a gente, né? Cada um é um [...] não que eu não admire as outras, mas, sei lá, ela não se importa em deixar a gente perguntar. Não faz. tudo rápido [...]

Puérpera Marília: sabe assim quando a gente se sente importante, valorizada, sem ser só mais uma [...] me parece que ela tem um jeito especial de prestar atenção no que cada uma tá sentindo.
Puérpera Carolina: não vê agora? Como é que ela tá lidando comigo? Eu acho que sou a única paciente que ela está atendendo. Sei que depois ela vai cuidar das outras, mas não vai me deixar sem respostas, me entende?

Puérpera Marilia: é, é isto mesmo. Ela não vai fazendo tudo rapidinho que nem as outras [...] dá um tempo pra gente pensar [...] aprender. Afinal, a gente nunca foi mãe antes [...] . ela dá atenção pro outro, sabe se expressar pra tirar aquela coisa assim,sabe? Isso é assim, assim e assim, deu [...] não, ela presta atenção, dá tempo pra gente [...].

\section{CONSIDERAÇÕES FINAIS}

De forma geral, o estudo mostra que as trabalhadoras transformam o tempo clínico em tempo narrativo, adotando duas pressuposições filosóficas gerais; a primeira, que identifica o cliente como um 'outro' envolvido em excepcionalidades, e a segunda, que sublinha a necessidade de particularização da assistência. Além disso, o tempo narrativo é evocado por meio de ações como a introdução de atos lúdicos que contribuem para induzir os atores sociais ao relaxamento, a utilização da linguagem não verbal e o exercício da paciência.

Percebe-se que neste modo de atuação, as trabalhadoras são reconhecidas pelos usuários, como promotoras de ações mais solidárias, terapêuticas e culturalmente centradas no sistema familiar de cuidados, além de colocar em prática um cuidado que promove os seus participantes, levando a que ambos, profissionais e famílias, se fortaleçam durante a experiência conjunta com o nascimento.

Os resultados alcançados mostram-se fecundos no sentido de deixar entrever algumas contribuições que poderão provocar reflexões ou mesmo algumas mudanças na arena da assistência de enfermagem relacionada ao processo do nascimento e à saúde reprodutiva e, especialmente, num 'modo de fazer' que não se limita aos cânones hegemônicos e pré-estabelecidos da temporalidade vivenciada em cenários clínicos.

\section{REFERÊNCIAS}

1 Goffman I. Manicômios, prisões e conventos. 2a ed. São Paulo: Perspectiva; 1999.

2 Kleinman A. The illnesss narrative: suffering, healing, and the human condiction. [s.1.]: Basic Books; 1988.

3 Mattingly C. Healing dramas and clinical plots: the narrative structure of experience. Cambridge: Cambridge University Press; 1998. 
4 Leininger MM. Cultural care diversity and universality: a theory of nursing. New York: National League for Nursing Press; 1991.

5 Geertz C. Nova luz sobre a antropologia. Rio de Janeiro: Jorge Zahar; 2001.

6 Leininger MM. Overview of the theory of culture care with the ethnonursing research method. J Trans Nurs. 1997 JanJun; 28 (2): 32-51.

7 Conselho Nacional de Saúde (BR). Resolução 196/96 de 10 de outubro. Aprovadas Diretrizes e Normas Regulamentadoras de Pesquisas Envolvendo Seres Humanos. Brasília: O Conselho; 1986.

8 Mulhall A. Anthropology, nursing, and midwiferry: a natural alliance? Int J Nurs Stud. 1996; 33 (6): 629-37.

9 Paim HHS. Marcas no corpo: gravidez e maternidade em grupos populares. In: Duarte LF, Leal OL, organizadores. Doença, sofrimento, perturbação: perspectivas etnográficas. Rio de Janeiro: Fiocruz; 1998. p. 31-48.
10 Good BJ, Delvecchio-Good MJ. "Fiction" and "historicity" in doctor's stories: social and narrative dimensions of learning medicine. In: Mattingly C, Garro LC, editors. Narrative and cultural construction of illness and healing. Berkerly: University of California Press; 2000. p. 50-69.

11 Kitzinger S. Authoritative touch in childbirth: a crosscultural approach. In: Davis-Floyd R, Sargent CF, editors. Childbirth and authoritative knowledge. Berkerley: University of California Press; 1997. p. 209-32.

12 Rezende ALM de. O quotidiano da enfermagem no trabalho em saúde. Belo Horizonte; 1997. Mimeografado.

13 Fonseca LMM, Scochi CGS, Bis CEF, Serra SOA. Utilizando a criatividade na educação em saúde em alojamento conjunto neonatal: opinião das puérperas sobre o uso de um jogo educativo. Rev Bras Enferm. 2000 Abr-Jun; 53 (2): 301-10.

14Lacharité C. Parenteral sensitivity: its role in the prevention of child maltreatment and the promotion of child wellbeing. Texto Contexto Enferm. 2003 Jul-Set; 12 (3): 275-9. 